\title{
Corrigendum \#2 to "On Synergistic Integration of Adaptive Dithering Based Internal Model Control for Hysteresis Compensation in Piezoactuated Nanopositioner"
}

\author{
Saikat Kumar Shome $\mathbb{D}^{1},{ }^{1}$ Mangal Prakash $\left(\mathbb{D},{ }^{2}\right.$ Sourav Pradhan $\mathbb{D},{ }^{2}$ and Arpita Mukherjee ${ }^{1}$ \\ ${ }^{1}$ Academy of Scientific and Innovative Research (AcSIR), \\ CSIR Central Mechanical Engineering Research Institute (CSIR-CMERI) Campus, Durgapur, India \\ ${ }^{2}$ Department of Electrical Engineering, University of Minnesota, Minneapolis, MN 55455, USA
}

Correspondence should be addressed to Saikat Kumar Shome; saikatkumarshome@gmail.com

Received 27 May 2018; Accepted 29 May 2018; Published 8 July 2018

Copyright (c) 2018 Saikat Kumar Shome et al. This is an open access article distributed under the Creative Commons Attribution License, which permits unrestricted use, distribution, and reproduction in any medium, provided the original work is properly cited.

In the article titled "On Synergistic Integration of Adaptive Dithering Based Internal Model Control for Hysteresis Compensation in Piezoactuated Nanopositioner" [1], the method description in Section 4 is to be elaborated. The actuator used in the research refers to packaged/preloaded type piezoelectric actuator of Physik Instrumente, and the maker of the cRIO-9073 system is National Instruments.

\section{References}

[1] S. K. Shome, M. Prakash, S. Pradhan, and A. Mukherjee, "On synergistic integration of adaptive dithering based internal model control for hysteresis compensation in piezoactuated nanopositioner," Mathematical Problems in Engineering, vol. 2015, Article ID 365141, 19 pages, 2015. 


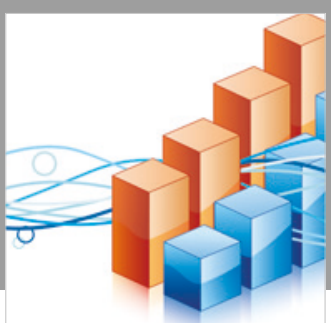

Advances in

Operations Research

\section{-n-m}
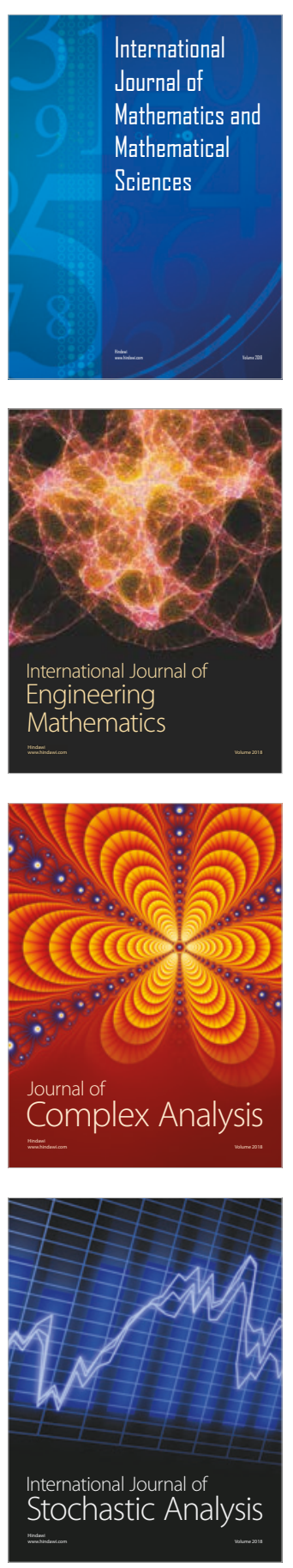
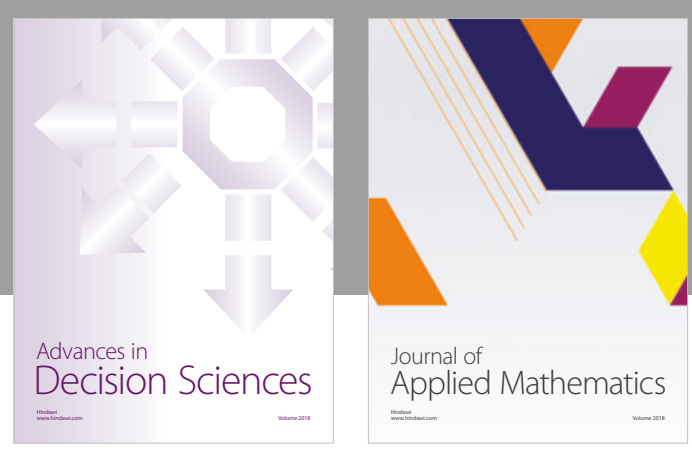

Journal of

Applied Mathematics
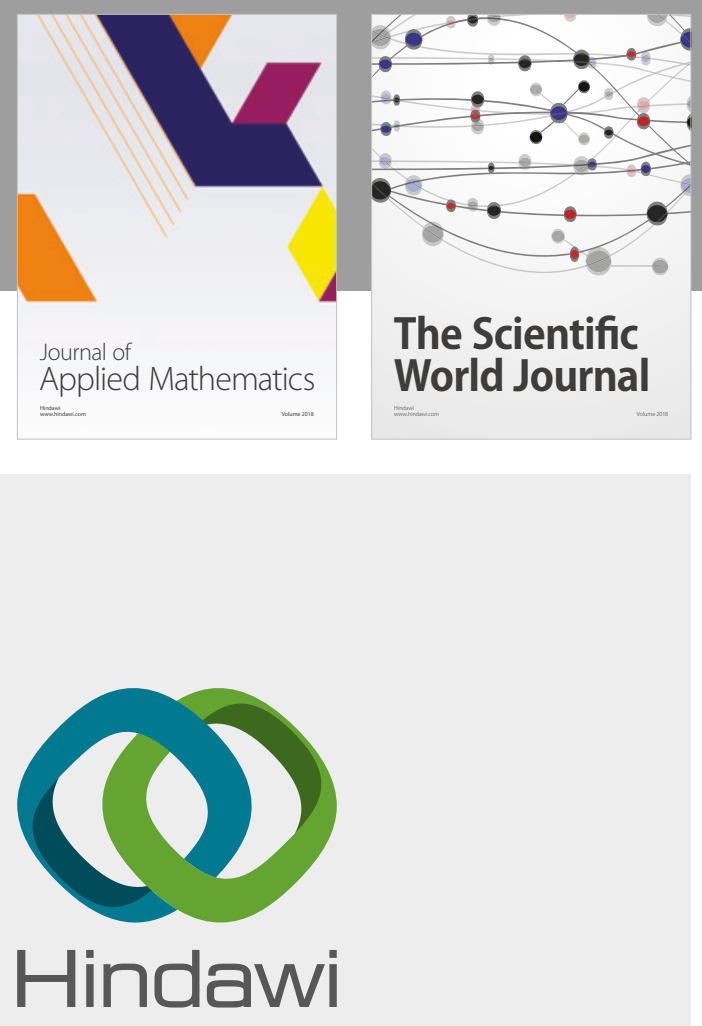

Submit your manuscripts at

www.hindawi.com

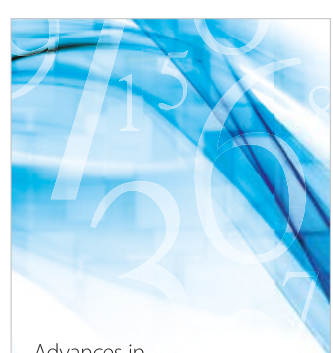

Advances in
Numerical Analysis
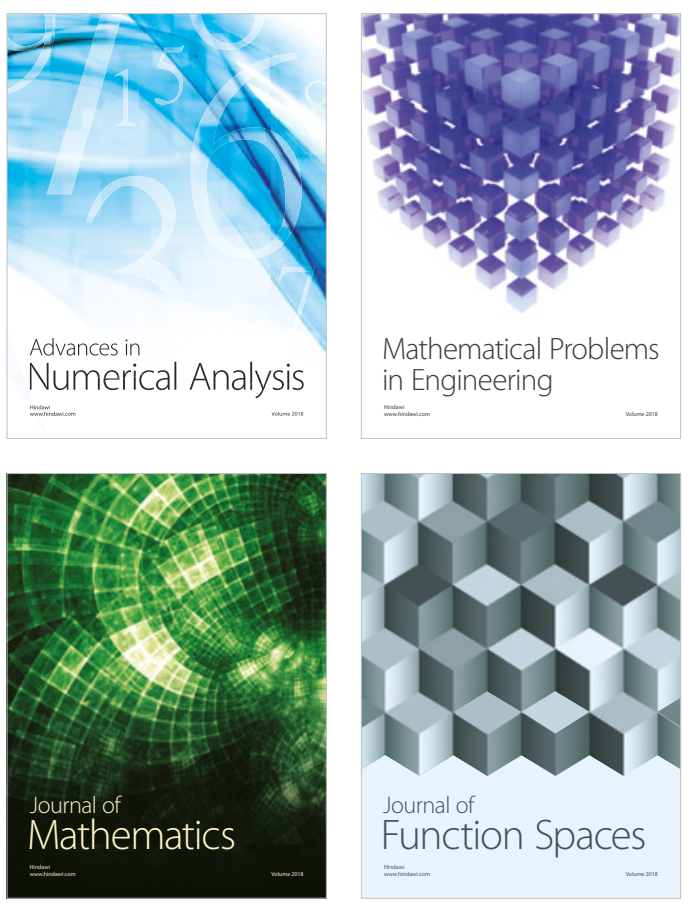

Mathematical Problems in Engineering

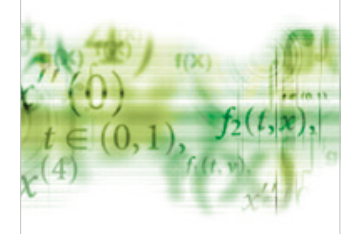

International Journal of

Differential Equations

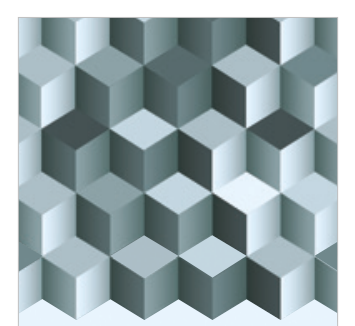

Journal of

Function Spaces

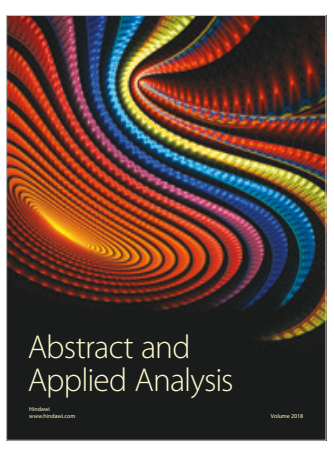

The Scientific

World Journal

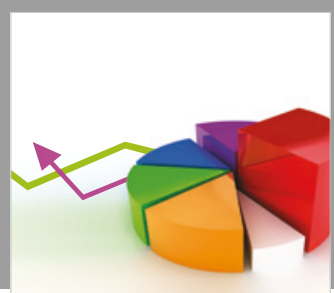

Journal of

Probability and Statistics
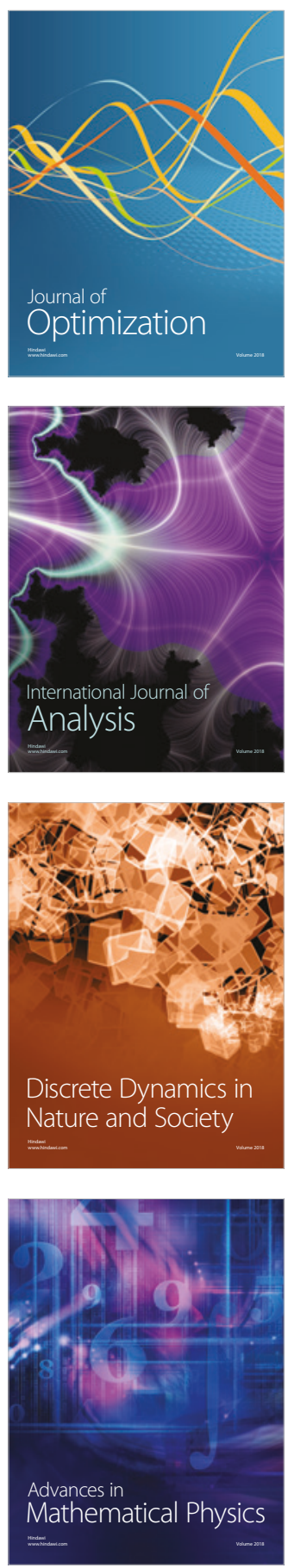